\title{
Prognostic value of Iymphocyte-to-monocyte ratio among Asian lung cancer patients: a systematic review and meta-analysis
}

\author{
Wen Li ${ }^{1,2, *}$, Guangzhi Ma ${ }^{2,3, *}$, Qiang Wu ${ }^{2, *}$, Yunfu Deng ${ }^{2}$, Ya Liu ${ }^{1}$ and Jing Wang ${ }^{1}$ \\ ${ }^{1}$ Department of Thyroid and Breast Surgery, West China Hospital, Sichuan University, Chengdu 610041, P.R. China \\ ${ }^{2}$ Cancer Center, West China Hospital, Sichuan University, Chengdu 610041, P.R. China \\ ${ }^{3}$ Department of Thoracic Surgery, West China Hospital, Sichuan University, Chengdu 610041, P.R. China \\ *These authors contributed equally to this work
}

Correspondence to: Jing Wang, email: wangj889@163.com

Keywords: lymphocyte to monocyte ratio (LMR), lung cancer, prognosis, meta-analysis

Received: July 08, $2017 \quad$ Accepted: August 04, $2017 \quad$ Published: August 28, 2017

Copyright: Li et al. This is an open-access article distributed under the terms of the Creative Commons Attribution License 3.0 (CC BY 3.0 ), which permits unrestricted use, distribution, and reproduction in any medium, provided the original author and source are credited.

\section{ABSTRACT}

Purpose: Numerous studies have reported the prognostic significance of lymphocyte-to-monocyte ratio (LMR) in malignancies, but its prognostic value among lung cancer remains controversial. This meta-analysis aimed to explore the prognostic significance of LMR in lung cancer patients.

Results: Eight studies including 3954 patients were included in this metaanalysis. Pooled results indicated that low LMR was significantly associated with poorer progression-free survival (hazard ratio (HR): $1.431,95 \%$ confidence interval (CI): 1.294-1.582, $p<0.001$ ) and overall survival (OS) (HR: 1.651, 95\% CI: $1.306-2.086, p<0.001$ ), compared with high LMR. Similar results were observed in subgroups regardless of treatment, LMR cut-off value, or districts. However, no significant correlation between the LMR and OS was observed in the small cell lung cancer $(S C L C)$ subgroup ( $H R=1.262,95 \%$ CI: $0.864-1.841, p=0.229$ ).

Materials and Methods: Identified literatures were extracted and retrieved from PubMed, Embase, Web of Science, and the Cochrane Library databases; All eligible studies focused on the association between LMR and the prognosis of lung cancer.

Conclusions: Low LMR is associated with poor outcomes among lung cancer patients. Further studies are needed to discuss the correlation between LMR and lung cancer prognosis.

\section{INTRODUCTION}

Lung cancer is one of the most commonly diagnosed cancer and the main cause of cancer morbidity worldwide [1]. Approximately 1.8 million new cases are diagnosed and causes around 1.4 million cancer-related deaths annually [2]. Although diagnosis and treatment strategy have improved in the past decades, the fiveyear survival rate of lung cancer remains unsatisfactory due to the risk of local recurrence or distal metastasis [3]. Studies have identified multiple prognostic factors in lung cancer patients [4], but promising markers that demonstrate prognostic value remain lacking [5]. Hence, identifying a novel potential biomarker useful in selecting appropriate treatment strategies and predicting prognosis is vital [6].

Systemic inflammatory response is correlated with formation and recurrence of various cancers [7-9]. Moreover, inflammation may cause the tumor microenvironments to promote cancer progression $[10,11]$. Studies have recently demonstrated that lymphocyte-tomonocyte ratio (LMR) is a prognostic indicator in some cancers, including hepatocellular cancer, endometrial cancer, breast cancer, and gastrointestinal cancer [6, 12-15]. Although the prognostic significance of LMR in lung cancer patients have been evaluated, contradicting conclusions were drawn. Hu et al. found that high LMR is a favorable factor and associated with longer OS compared with low 
LMR [16]. However, Cao et al. found no association between LMR and OS in lung cancer [17]. Thus, we performed a meta-analysis to determine the prognostic value of LMR in lung cancer.

\section{RESULTS}

\section{Literature search}

Our search strategy involved screening of 63 potentially relevant papers (Figure 1). Based on their titles and abstracts, 11 studies were eventually assessed. After reading their full texts, eight studies with a total of 3954 patients were included in this meta-analysis [16-23].

\section{Characteristics of the eligible studies}

The eight studies were retrospective studies, published between 2014 and 2017, and with a sample size of 74-1453 (Table 1). The patients' median age ranged from 50 years to 69 years. As for ethnicity, all of the studies included Asian populations. The LMR cut-off values ranged from 2.62 to 4.56. Seven studies reported disease-free survival (DFS) or PFS, and all studies determined the OS. HRs and 95\% CIs were determined directly from these studies. The NOS scores of the eight studies varied from 6 to 8 .

\section{Correlation between LMR and PFS}

The effect of LMR on PFS was evaluated in seven studies, which include 3247 patients. The results showed that patients with low LMR displayed worse PFS than those with high LMR (HR $=1.431,95 \%$ CI: 1.294-1.582, $P<0.001$; Figure 2A). No significant heterogeneity $\left(I^{2}=39.30 \%, p=0.129\right)$ was found and thus fixed-effect model was used.

\section{Correlation between LMR and OS}

All of the eight studies were included in the analysis of OS. As shown in Figure 2B, lung cancer patients with low

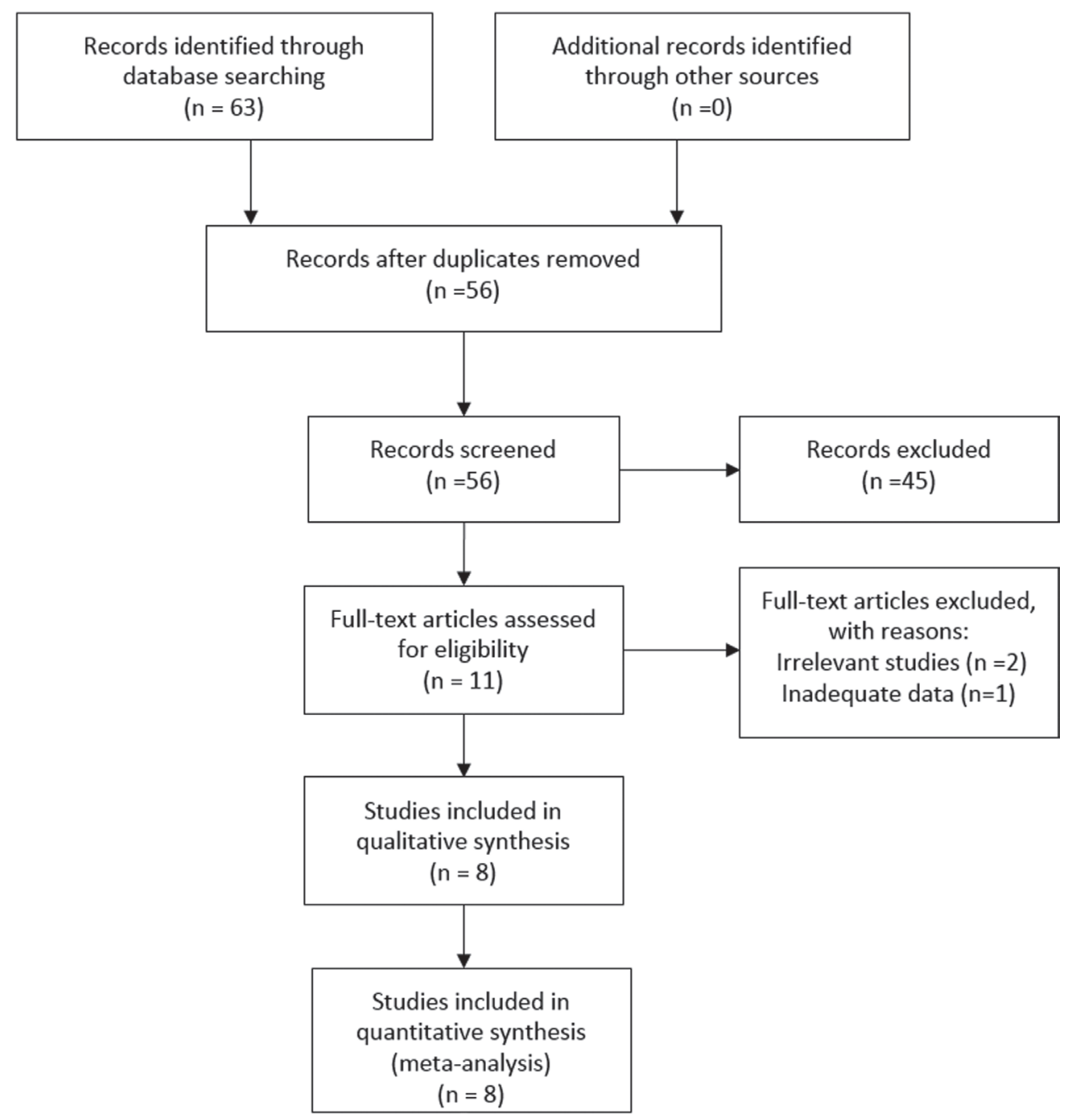

Figure 1: The selection process for eligible studies. 
Table 1: Characteristics of the included studies

\begin{tabular}{|c|c|c|c|c|c|c|c|c|c|c|c|}
\hline Author & Year & Country & $\mathrm{N}$ of patients $(\mathrm{F} / \mathrm{M})$ & Median age & $\begin{array}{l}\text { Histological } \\
\text { subtype }\end{array}$ & Tumor stage & Treatment & $\begin{array}{l}\text { Survival } \\
\text { Reported }\end{array}$ & $\begin{array}{l}\text { Cut-off value } \\
\text { of LMR }\end{array}$ & $\begin{array}{c}\text { HR } \\
\text { estimation }\end{array}$ & $\begin{array}{l}\text { NOS } \\
\text { scores }\end{array}$ \\
\hline Hu et al. & 2014 & China & $1453(418 / 1035)$ & 59 & NSCLC/SCLC & I-III & Surgery & DFS and OS & 3.68 & MA. & 8 \\
\hline Lin et al. & 2014 & China & $370(157 / 213)$ & 63.6 & NSCLC & IIIB-IV & Non-surgery & DFS and OS & 4.56 & MA. & 7 \\
\hline Go et al. & 2014 & Korea & $188(74 / 114)$ & 69 & SCLC & LD/ED/LHD & Non-surgery & PFS and OS & 4.19 & MA. & 7 \\
\hline Chen et al. & 2015 & China & $235(131 / 104)$ & 65.2 & NSCLC & IIIB-IV & Non-surgery & PFS and OS & 3.29 & MA. & 6 \\
\hline Wang et al. & 2015 & China & $74(39 / 35)$ & 50 & NSCLC & I-IV & Various & PFS and OS & 3.82 & MA. & 6 \\
\hline Xia et al. & 2016 & China & $439(152 / 287)$ & 62 & NSCLC & I & Surgery & RFS and OS & 4.00 & MA. & 8 \\
\hline Song et al. & 2016 & China & $488(129 / 359)$ & 64 & NSCLC & I-II & Surgery & PFS and OS & 4.50 & MA. & 7 \\
\hline Cao et al. & 2017 & China & $707(253 / 454)$ & 56.2 & SCLC & LD ED & Non-surgery & OS & 2.62 & MA. & 8 \\
\hline
\end{tabular}

N: number; NSCLC: non-small cell lung cancer; SCLC: small cell lung cancer; LD: limited-stage disease; ED: extensive-stage disease; LDH: lactate dehydrogenase; DFS: disease-free survival; RFS: recurrencefree survival; OS: overall survival; MA: multivariate analysis; NOS: Newcastle-Ottawa Scale.

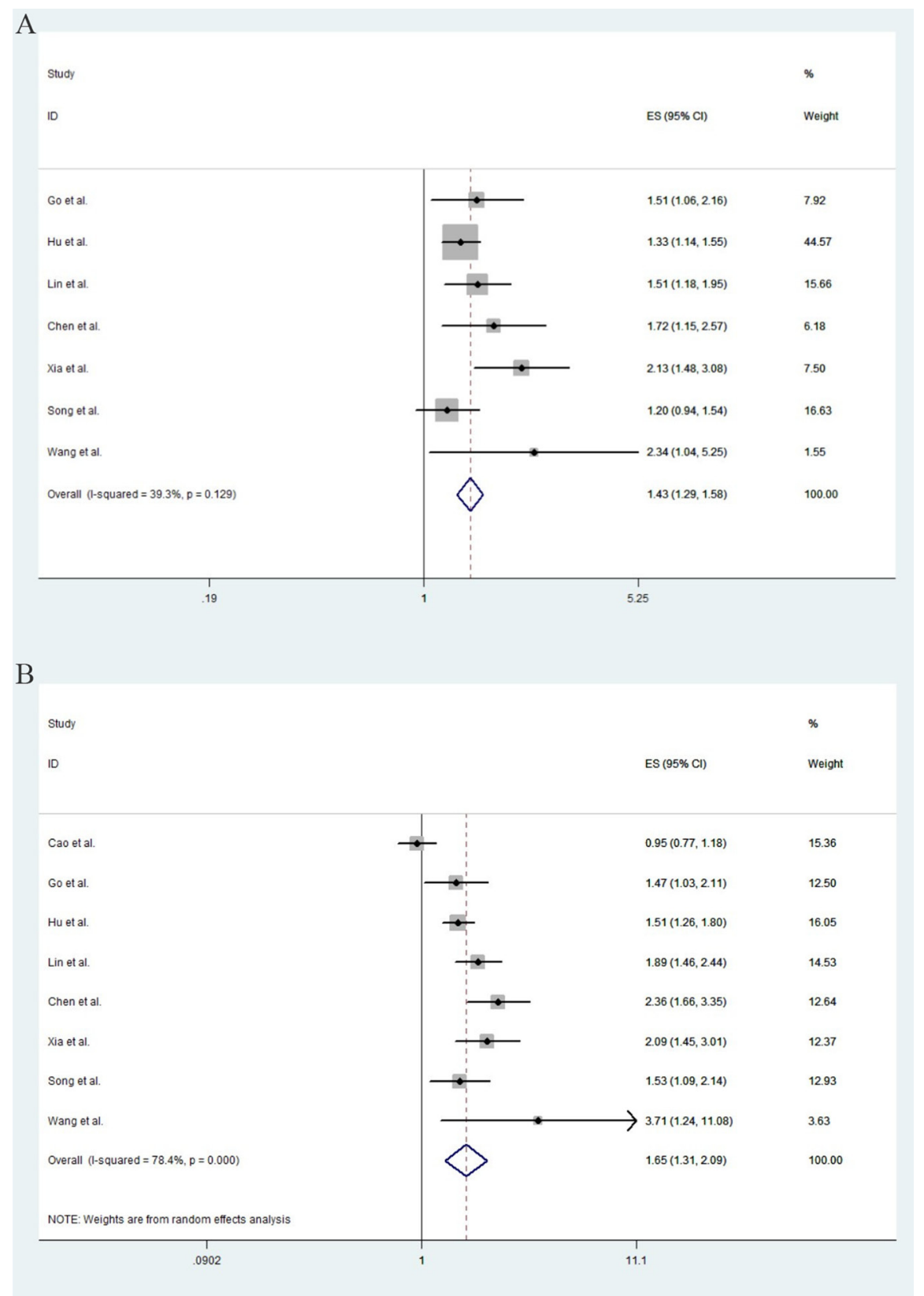

Figure 2: The pooled estimated survival (ES) (hazard ratios) for PFS (A) and OS (B) in Asian lung cancer patients with low LMR. 
Table 2: Meta-analyses of correlation between LMR and survival of lung cancer patients

\begin{tabular}{|c|c|c|c|c|}
\hline & $N$ of studies & HR (95\% CI) & Log-rank $P$ & Heterogeneity $\left(p, I^{2}\right)$ \\
\hline Total PFS & 7 & $1.431(1.294-1.582)$ & $<0.001$ & $0.129,39.3 \%$ \\
\hline NSCLC PFS & 6 & $1.486(1.269-1.740)$ & $<0.001$ & $0.052,54.3 \%$ \\
\hline SCLC PFS & 1 & $1.509(1.056-2.157)$ & 0.024 & - \\
\hline Surgery PFS & 3 & $1.443(1.113-1.872)$ & 0.006 & $0.033,70.6 \%$ \\
\hline Non-surgery PFS & 3 & $1.553(1.292-1.868)$ & $<0.001$ & $0.863,0.0 \%$ \\
\hline Cut-off value $\geq 4$ PFS & 4 & $1.516(1.213-1.893)$ & $<0.001$ & $0.225,32.9 \%$ \\
\hline Cut-off value $<4$ PFS & 3 & $1.394(1.213-1.602)$ & $<0.001$ & $0.01,78.1 \%$ \\
\hline Chinese PFS & 6 & $1.425(1.283-1.582)$ & $<0.001$ & $0.081,49.0 \%$ \\
\hline Korean PFS & 1 & $1.509(1.056-2.157)$ & 0.024 & - \\
\hline Total OS & 8 & $1.651(1.306-2.086)$ & $<0.001$ & $<0.001,78.4 \%$ \\
\hline NSCLC OS & 6 & $1.751(1.553-1.975)$ & $<0.001$ & $0.115,43.6 \%$ \\
\hline SCLC OS & 3 & $1.262(0.864-1.841)$ & 0.229 & $0.04,68.9 \%$ \\
\hline Surgery OS & 3 & $1.593(1.379-1.840)$ & $<0.001$ & $0.279,21.6 \%$ \\
\hline Non-Surgery OS & 4 & $1.563(1.025-2.386)$ & 0.038 & $<0.001,88.4 \%$ \\
\hline Cut-off value $\geq 4$ OS & 4 & $1.747(1.488-2.050)$ & $<0.001$ & $0.432,0 \%$ \\
\hline Cut-off value $<4$ OS & 4 & $1.630(1.053-2.521)$ & 0.028 & $<0.001,87.8 \%$ \\
\hline Chinese OS & 7 & $1.687(1.293-2.199)$ & $<0.001$ & $<0.001,81.4 \%$ \\
\hline Korean OS & 1 & $1.472(1.029-2.106)$ & 0.034 & - \\
\hline
\end{tabular}

$N$ : number; HR: hazard ratio; CI: confidence interval; PFS: progression-free survival; OS: overall survival; NSCLC: non-small cell lung cancer; SCLC: small cell lung cancer.

LMR displayed a significantly poorer OS than those with high LMR $(\mathrm{HR}=1.651,95 \%$ CI: $1.306-2.086, p<0.001)$. A significant heterogeneity among these studies was observed $\left(I^{2}=78.40 \%, p<0.001\right)$, and random-effect model was used.

\section{Subgroup analyses}

The included studies were divided into subgroups according to the data extracted, as follows: (1) Pathology (NSCLC/SCLC); (2) Therapy (Surgery/Non-surgery); (3) LMR value $(\geq 4 /<4)$; and (4) Chinese patients.

\section{NSCLC/SCLC}

Six studies on NSCLC were conducted, and the pooled HRs for PFS and OS were 1.486 (CI: 1.269-1.740, $p<0.001, I^{2}=54.30 \%$ ) and 1.751 (CI: 1.553-1.975, $p<0.001, I^{2}=43.60 \%$ ), respectively. As for SCLC patients, OS was reported in three literatures, and the pooled result for OS was 1.262 (CI: 0.864-1.841, $p=0.229)$. Heterogeneity was significant $(p=0.04$, $I^{2}=68.9 \%$ ) hence random-effect model was applied.

\section{Surgery/non-surgery}

Three studies focused on patients that underwent surgery. The combined HR for PFS was 1.443
(CI: $1.113-1.872, p=0.006, I^{2}=70.6 \%$ ). The pooled OS was 1.593 (CI: $1.379-1.840, p<0.001$ ); no significant heterogeneity $\left(p=0.279, I^{2}=21.6 \%\right)$ was found and fixed-effect model was used. With regard to non-surgery patients, the pooled PFS and OS were 1.553 (CI: 1.292$\left.1.868, p<0.001, I^{2}=0.0 \%\right)$ and $1.563(1.025-2.386, p=$ $0.038, I^{2}=88.4 \%$ ), respectively.

\section{LMR value}

When LMR was no less than 4, the pooled HR for PFS and OS was 1.516 (CI: 1.213-1.893, $p<0.001$, $I^{2}=32.9 \%$ ) and 1.747 (CI: 1.488-2.05, $p<0.001$, $I^{2}=0 \%$ ). As for studies that reported LMRs less than 4, the combined HR for PFS was 1.394 (1.213-1. 602, $\left.p<0.001, I^{2}=78.1 \%\right)$ and the pooled HR for OS was $1.630\left(1.053-2.521, p=0.028, I^{2}=87.80 \%\right)$.

\section{Chinese patients}

Seven studies were conducted in China. The PFS reported in six studies were pooled, and the combined HR was 1.425 (CI: 1.283-1.582, $p<0.001, I^{2}=$ $49.00 \%$ ). All literatures examined OS, and the pooled result was 1.687 (CI: $1.293-2.199, p<0.001, I^{2}=$ $81.40 \%$ ). All pooled results are shown in Table 2. 


\section{Publication bias}

Publication bias was not significant in the current meta-analysis based on the plots of publication shown in Figure 3.

\section{DISCUSSION}

Inflammation is critical in tumor growth, invasion, and metastasis; many inflammatory indicators, including neutrophilocyte-to-lymphocyte ratio, derived neutrophilcyte-to-lymphocyte ratio, platelet-to-lymphocyte ratio, and LMR, are prognostic factors in various cancers $[15,19,24-26]$. This meta-analysis is the first to determine the prognostic effect of LMR on lung cancer. Our results demonstrated a significantly strong correlation between LMR and prognosis of lung cancer patients, and high LMR indicated longer PFS and OS compared with low LMR. Moreover, the same outcomes were found in different subgroups regardless of treatment, LMR cut-off value, and districts.

Subgroup analysis was performed to detect the potential heterogeneity among included studies (Table 2). The results showed that high LMR revealed a favorable PFS and OS in NSCLC patients. Additionally, no significant difference between LMR and OS was found in SCLC patients in this study, and similar results were reported by $\mathrm{Hu}$ et al. and Cao et al. [17, 22]. By contrast, Go et al. showed a different result, where high LMR also indicated better OS in SCLC [16]. However, the difference in survival was observed only in patients with limitedstage disease (ED), possibly leading to the difference in the results between that study and ours.

The subgroup analysis showed that high LMR indicated a better PFS and OS in patients who underwent surgery or not. However, no significant difference between LMR and OS in patients who did not receive operation was reported in Cao et al.'s study, which included the second largest number of cases (707) [17]. This result indicated that the potential roles of LMR must be verified in further research for this subgroup of patients.

Considering that the published studies used various cut-off values ranging from 2.62 to 4.56 , our subgroup analysis indicated that the prognostic value of LMR was significant regardless of cut-off value. Moreover, the analysis of geographic area subgroup indicated that the prognostic value of LMR was observed in China and Korea. However, only one study involving 188 Korean patients was included in the meta-analysis; therefore, the conclusion of the study performed in Korea should be considered with caution, and more studies should be performed to verify the results.

Although the exact mechanisms have not yet been elucidated, either absolute lymphocyte or monocyte count is significantly associated with the prognosis of various cancers; moreover, LMR has been extensively reported and viewed as a promising prognostic indicator in malignancies [27-29]. Tumor-infiltrating lymphocytes are associated with a favorable prognosis in various tumors. By contrast, low lymphocyte count, which leads to inferior survival in multiple cancers, possibly results in an insufficient immunological reaction [30]. Moreover, tumorassociated macrophages (TAMs) derived from circulating monocytes recruit and constitute the inflammatory infiltrate and promote cancer proliferation, angiogenesis, and metastasis [31]. Studies have demonstrated that the infiltration of TAMs is associated with cancer survival, and the peripheral blood monocytes may reflect the formation or presence of TAMs $[32,33]$. In reference to these factors, high LMR may reflect the inflammatory tumor microenvironment and inhibits tumor progression.

There are several limitations in this meta-analysis due to practical constraints. Firstly, a limited number of eligible studies exist. All articles included in this meta-analysis were conducted in Asian countries, and all publications used in data synthesis were published in English, suggesting that some eligible studies may have been excluded due to language constraints. Second, heterogeneity was significant
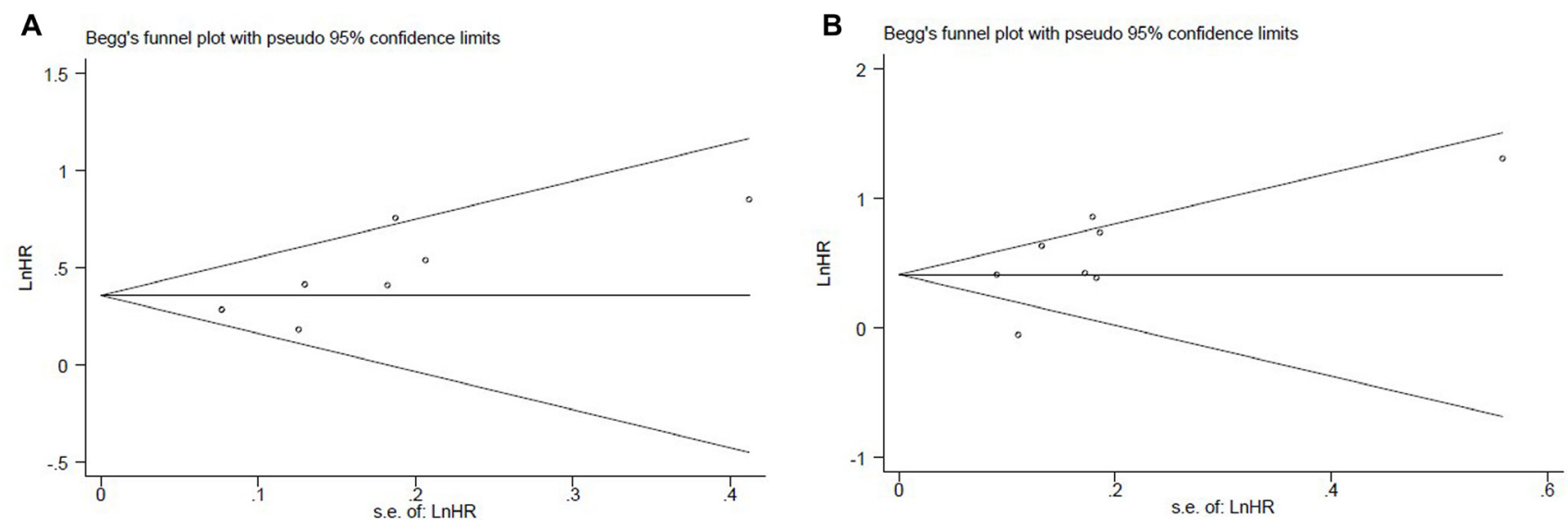

Figure 3: The Begg's publication bias plots of the studies that reported the correlation between low LMR and PFS (A) and OS (B) in patients that developed lung cancer. 
in various pooled results. Inconsistent issues within each study, such as therapy options, tumor stage, or gender, may have caused such heterogeneity. Moreover, due to lack of background information, we failed to perform subgroup analyses on parameters such as gender or tumor stage. Additionally, the cut-off values used to define LMR, as mentioned, were inconsistent and thus we could not identify which cut-off value was the most reliable. Nonetheless, with the use of a detailed protocol and a carefully pooled data and random-effect model, the impact of heterogeneity was constrained to the minimum, and the pooled results were guaranteed reliable.

To conclude, our results demonstrated that elevated LMR results in a favorable outcome in lung cancer patients. Given that the use of LMR as indicator is facile and low cost, LMR is a potential marker for patient prognosis.

\section{MATERIALS AND METHODS}

\section{Search strategies}

We searched the PubMed, Embase, Web of Science, and the Cochrane Library databases to identify relevant studies published up to May 2017. Our search terms included "lung neoplasm" or "lung carcinoma" or "lung cancer" or "lung tumor" or "cancer of lung" or "lymphocyte to monocyte ratio" or "lymphocyte monocyte ratio" or "lymphocyte-to-monocyte ratio" or"LMR". All relevant studies were included based on their titles and abstracts. Moreover, their reference lists were reviewed to identify other relevant articles.

\section{Inclusion criteria}

The inclusion criteria were as follows: (1) the study evaluated the association between LMR and prognosis; (2) the study includes adequate data for calculation of the hazard ratio (HR) and their corresponding 95\% confidence intervals (CIs); (3) the cut off value for LMR was reported; and (4) the articles published in English.

\section{Exclusion criteria}

The exclusion criteria were as followed: (1) studies published as reviews, letters, comments, or case reports; (2) studies without adequate data for the calculation of HR and CI; (3) overlapped or duplicated data; and (4) studies published in languages other than English.

\section{Data extraction and quality assessment}

Two reviewers (WL and GM) searched the manuscripts independently and then they compared the data they gathered; any dispute was settled by the third investigator. The following information were extracted: first author's name, year of publication, country, ethnicity, number of cases, demographic characteristics (e.g., patient age and gender), cut-off value, treatment, and prognosis.

Multivariate outcomes were extracted when both multivariate and univariate analyses were performed in the included studies. The Newcastle-Ottawa Scale (NOS) was used to evaluate the qualities of all the included studies [34]. This evaluation tool covered the selection, comparability, and clinical outcomes. Studies with a score of $\geq 6$ were defined as high-quality studies.

\section{Statistical analysis}

Survival data including progression-free survival (PFS) and OS, were reported in terms of HRs and 95\% CIs. The heterogeneity of all the studies was assessed by Cochran's $Q$ and Higgins $I^{2}$ tests [35]. Random-effect model was used when the heterogeneity was significant ( $p<0.05 / I^{2}>50 \%$ ); otherwise, fixed-effect model was used [36]. Sensitivity analysis was performed to estimate the stability of the result by excluding individual studies. Moreover, Begg's tests was used to assess the presence of a potential publication bias [37]. If $p$ value is no more than 0.05 , it is considered statistical significance. All data analyses were performed using Stata 12.0 software (StataCorp LP, TX, USA).

\section{CONFLICTS OF INTEREST}

None.

\section{REFERENCES}

1. Dela Cruz CS, Tanoue LT, Matthay RA. Lung cancer: epidemiology, etiology, and prevention. Clin Chest Med. 2011; 32:605-44. https://doi.org/10.1016/j.ccm.2011.09.001.

2. Torre LA, Bray F, Siegel RL, Ferlay J, Lortet-Tieulent J, Jemal A. Global cancer statistics, 2012. CA Cancer J Clin. 2015; 65:87-108. https://doi.org/10.3322/caac.21262.

3. Siegel R, Ma J, Zou Z, Jemal A. Cancer statistics, 2014. CA Cancer J Clin. 2014; 64:9-29. https://doi.org/10.3322/ caac. 21208 .

4. Hwang JA, Song JS, Yu DY, Kim HR, Park HJ, Park YS, Kim WS, Choi CM. Peroxiredoxin 4 as an independent prognostic marker for survival in patients with early-stage lung squamous cell carcinoma. Int J Clin Exp Pathol. 2015; 8:6627-35.

5. Diamandis EP, Hoffman BR, Sturgeon CM. National Academy of Clinical Biochemistry Laboratory Medicine Practice Guidelines for the Use of Tumor Markers. Clin Chem. 2008; 54:1935-39. https://doi.org/10.1373/ clinchem.2008.105494.

6. Song W, Tian C, Wang K, Zhang RJ, Zou SB. The pretreatment lymphocyte to monocyte ratio predicts clinical outcome for patients with hepatocellular carcinoma: A metaanalysis. Sci Rep. 2017; 7:46601. https://doi.org/10.1038/ srep46601. 
7. Qu J, Qu X, Li Z, Zhang J, Teng Y, Jin B, Zhao M, Yu P, Wang Z, Liu Y. Role of patient-, tumor- and systemic inflammatory response-related factors in predicting survival of patients with node-negative gastric cancer. Tumour Biol. 2017; 39. https://doi.org/10.1177/1010428317698374.

8. Arigami T, Uenosono Y, Ishigami S, Okubo K, Kijima T, Yanagita S, Okumura H, Uchikado Y, Kijima Y, Nakajo A, Kurahara H, Kita Y, Mori S, et al. A Novel Scoring System Based on Fibrinogen and the Neutrophil-Lymphocyte Ratio as a Predictor of Chemotherapy Response and Prognosis in Patients with Advanced Gastric Cancer. Oncology. 2016; 90:186-92. https://doi.org/10.1159/000444494.

9. Wen J, Yang Y, Ye F, Huang X, Li S, Wang Q, Xie X. The preoperative plasma fibrinogen level is an independent prognostic factor for overall survival of breast cancer patients who underwent surgical treatment. Breast. 2015; 24:745-50. https://doi.org/10.1016/j.breast.2015.09.007.

10. Grivennikov SI, Greten FR, Karin M. Immunity, inflammation, and cancer. Cell. 2010; 140:883-99. https:// doi.org/10.1016/j.cell.2010.01.025.

11. Arigami T, Okumura H, Matsumoto M, Uchikado Y, Uenosono Y, Kita Y, Owaki T, Mori S, Kurahara H, Kijima Y, Ishigami S, Natsugoe S. Analysis of the Fibrinogen and Neutrophil-Lymphocyte Ratio in Esophageal Squamous Cell Carcinoma: A Promising Blood Marker of Tumor Progression and Prognosis. Medicine (Baltimore). 2015; 94:e1702. https://doi.org/10.1097/MD.0000000000001702.

12. Stotz M, Liegl-Atzwanger B, Posch F, Mrsic E, Thalhammer M, Stojakovic T, Bezan A, Pichler M, Gerger A, Szkandera J. Blood-Based Biomarkers Are Associated with Disease Recurrence and Survival in Gastrointestinal Stroma Tumor Patients after Surgical Resection. PLoS One. 2016; 11:e0159448. https://doi.org/10.1371/journal. pone. 0159448 .

13. Wen J, Ye F, Huang X, Li S, Yang L, Xiao X, Xie X. Prognostic Significance of Preoperative Circulating Monocyte Count in Patients With Breast Cancer: Based on a Large Cohort Study. Medicine (Baltimore). 2015; 94:e2266. https://doi.org/10.1097/MD.0000000000002266.

14. Ding L, Ding Y, Mao XH, Zhao JF, Zhou HJ. Retrospective study of the prognostic significance of neutrophil-tolymphocyte ratio for postsurgical outcomes of patients with endometrial carcinoma. Int J Gynaecol Obstet. 2017; 138:311-19. https://doi.org/10.1002/ijgo.12230.

15. Ghanim B, Schweiger T, Jedamzik J, Glueck O, Glogner C, Lang G, Klepetko W, Hoetzenecker K. Elevated inflammatory parameters and inflammation scores are associated with poor prognosis in patients undergoing pulmonary metastasectomy for colorectal cancer. Interact Cardiovasc Thorac Surg. 2015; 21:616-23. https://doi. org/10.1093/icvts/ivv206.

16. Go SI, Kim RB, Song HN, Kang MH, Lee US, Choi HJ, Lee SJ, Cho YJ, Jeong YY, Kim HC, Lee JD, Kim SH, Kang JH, et al. Prognostic significance of the lymphocyteto-monocyte ratio in patients with small cell lung cancer.
Med Oncol. 2014; 31:323. https://doi.org/10.1007/s12032014-0323-y.

17. Cao S, Jin S, Shen J, Cao J, Zhang H, Meng Q, Wang C, Zhang A, Zhang P, Yu Y. Selected patients can benefit more from the management of etoposide and platinum-based chemotherapy and thoracic irradiation-a retrospective analysis of 707 small cell lung cancer patients. Oncotarget. 2017; 8:8657-69. https://doi.org/10.18632/ oncotarget.14395.

18. Xia H, Sun Z, Deng L, Zhu D, Wang D. Prognostic Significance of the Preoperative Lymphocyte to Monocyte Ratio in Patients With Stage I Non-Small Cell Lung Cancer Undergoing Complete Resection. Cancer Invest. 2016; 34:378-84. https://doi.org/10.1080/07357907.2016.1213276.

19. Wang L, Long W, Li PF, Lin YB, Liang Y. An Elevated Peripheral Blood Monocyte-to-Lymphocyte Ratio Predicts Poor Prognosis in Patients with Primary Pulmonary Lymphoepithelioma-Like Carcinoma. PLoS One. 2015; 10:e0126269. https://doi.org/10.1371/journal. pone. 0126269 .

20. Song YJ, Wang LX, Hong YQ, Lu ZH, Tong Q, Fang XZ, Tan J. Lymphocyte to monocyte ratio is associated with response to first-line platinum-based chemotherapy and prognosis of early-stage non-small cell lung cancer patients. Tumour Biol. 2016; 37:5285-93. https://doi.org/10.1007/ s13277-015-4397-8.

21. Lin GN, Peng JW, Xiao JJ, Liu DY, Xia ZJ. Prognostic impact of circulating monocytes and lymphocyte-tomonocyte ratio on previously untreated metastatic nonsmall cell lung cancer patients receiving platinum-based doublet. Med Oncol. 2014; 31:70. https://doi.org/10.1007/ s12032-014-0070-0.

22. Hu P, Shen H, Wang G, Zhang P, Liu Q, Du J. Prognostic significance of systemic inflammation-based lymphocytemonocyte ratio in patients with lung cancer: based on a large cohort study. PLoS One. 2014; 9:e108062. https://doi. org/10.1371/journal.pone.0108062.

23. Chen YM, Lai CH, Chang HC, Chao TY, Tseng CC, Fang WF, Wang CC, Chung YH, Wang YH, Su MC, Huang KT, Chen HC, Chang YC, Lin MC. Baseline and Trend of Lymphocyteto-Monocyte Ratio as Prognostic Factors in Epidermal Growth Factor Receptor Mutant Non-Small Cell Lung Cancer Patients Treated with First-Line Epidermal Growth Factor Receptor Tyrosine Kinase Inhibitors. PLoS One. 2015; 10:e0136252. https://doi.org/10.1371/journal.pone.0136252.

24. Rimando J, Campbell J, Kim JH, Tang SC, Kim S. The Pretreatment Neutrophil/Lymphocyte Ratio Is Associated with All-Cause Mortality in Black and White Patients with Non-metastatic Breast Cancer. Front Oncol. 2016; 6:81. https://doi.org/10.3389/fonc.2016.00081.

25. Koh $\mathrm{CH}$, Bhoo-Pathy $\mathrm{N}, \mathrm{Ng} \mathrm{KL}$, Jabir RS, Tan GH, See MH, Jamaris S, Taib NA. Utility of pre-treatment neutrophil-lymphocyte ratio and platelet-lymphocyte ratio as prognostic factors in breast cancer. Br J Cancer. 2015; 113:150-58. https://doi.org/10.1038/bjc.2015.183. 
26. Schulz GB, Grimm T, Buchner A, Jokisch F, Grabbert M, Schneevoigt BS, Kretschmer A, Stief CG, Karl A. Prognostic Value of the Preoperative Platelet-to-leukocyte Ratio for Oncologic Outcomes in Patients Undergoing Radical Cystectomy for Bladder Cancer. Clin Genitourin Cancer. 2017; 15:e915-e921. https://doi.org/10.1016/j. clgc.2017.05.009.

27. Ni XJ, Zhang XL, Ou-Yang QW, Qian GW, Wang L, Chen S, Jiang YZ, Zuo WJ, Wu J, Hu X, Shao ZM. An elevated peripheral blood lymphocyte-to-monocyte ratio predicts favorable response and prognosis in locally advanced breast cancer following neoadjuvant chemotherapy. PLoS One. 2014; 9:e111886. https://doi.org/10.1371/journal. pone. 0111886 .

28. Kumagai S, Marumo S, Shoji T, Sakuramoto M, Hirai T, Nishimura T, Arima N, Fukui M, Huang CL. Prognostic impact of preoperative monocyte counts in patients with resected lung adenocarcinoma. Lung Cancer. 2014; 85:45764. https://doi.org/10.1016/j.lungcan.2014.06.015.

29. Tanrikulu AC, Abakay A, Komek H, Abakay O. Prognostic value of the lymphocyte-to-monocyte ratio and other inflammatory markers in malignant pleural mesothelioma. Environ Health Prev Med. 2016; 21:304-11. https://doi. org/10.1007/s12199-016-0530-6.

30. Chen KJ, Zhou L, Xie HY, Ahmed TE, Feng XW, Zheng SS. Intratumoral regulatory $\mathrm{T}$ cells alone or in combination with cytotoxic $\mathrm{T}$ cells predict prognosis of hepatocellular carcinoma after resection. Med Oncol. 2012; 29:1817-26. https://doi.org/10.1007/s12032-011-0006-x.

31. Mantovani A, Bottazzi B, Colotta F, Sozzani S, Ruco L. The origin and function of tumor-associated macrophages. Immunol Today. 1992; 13:265-70. https://doi. org/10.1016/0167-5699(92)90008-U.
32. Lin JY, Li XY, Tadashi N, Dong P. Clinical significance of tumor-associated macrophage infiltration in supraglottic laryngeal carcinoma. Chin J Cancer. 2011; 30:280-86. https://doi.org/10.5732/cjc.010.10336.

33. Clear AJ, Lee AM, Calaminici M, Ramsay AG, Morris KJ, Hallam S, Kelly G, Macdougall F, Lister TA, Gribben JG. Increased angiogenic sprouting in poor prognosis FL is associated with elevated numbers of CD163+ macrophages within the immediate sprouting microenvironment. Blood. 2010; 115:5053-56. https://doi.org/10.1182/ blood-2009-11-253260.

34. Stang A. Critical evaluation of the Newcastle-Ottawa scale for the assessment of the quality of nonrandomized studies in meta-analyses. Eur J Epidemiol. 2010; 25:603-05. https://doi.org/10.1007/s10654-010-9491-z.

35. Higgins J, Thompson S, Deeks J, Altman D. Statistical heterogeneity in systematic reviews of clinical trials: a critical appraisal of guidelines and practice. J Health Serv Res Policy. 2002; 7:51-61. https://doi. org/10.1258/1355819021927674.

36. Kontopantelis E, Reeves D. Performance of statistical methods for meta-analysis when true study effects are non-normally distributed: A simulation study. Stat Methods Med Res. 2012; 21:409-26. https://doi. org/10.1177/0962280210392008.

37. Egger M, Davey Smith G, Schneider M, Minder C. Bias in meta-analysis detected by a simple, graphical test. BMJ. 1997; 315:629-34. https://doi.org/10.1136/ bmj.315.7109.629. 